Neuroethics Now welcomes articles addressing the ethical application of neuroscience in research and patient care, as well as its impact on society.

\title{
Mosaic Decisionmaking and Reemergent Agency after Severe Brain Injury
}

\author{
JOSEPH J. FINS
}

\begin{abstract}
In this article, I will discuss the challenge posed by the reemergent agency of individuals with severe brain injury whose ability to communicate has been partially restored by neuroprosthetics, drugs, and rehabilitation. Instead of categorically distinguishing patients as either competent or incompetent, these technologies necessitate a more nuanced approach to intermediate states of decisionmaking capacity. This indeterminacy is addressed through a mosaic approach to decisionmaking, which seeks to achieve a proportionate and prudent balance between unbridled self-determination and conventional surrogate representation.
\end{abstract}

Keywords: brain injury; agency; competence; decisionmaking capacity; surrogate decisionmaking; neuroethics; minimally conscious state

\section{Reemergent Agency and Neurotechnology}

The advent of neurotechnologies that partially restore the decisionmaking capacity of individuals with severe brain injury, or augment their diminished abilities to express their will, has created an ethical challenge worthy of this technological achievement. ${ }^{1}$ Instead of categorically distinguishing patients as either competent or incompetent, as required by the law, these technologies necessitate a more nuanced approach to intermediate states of decisionmaking capacity. The indeterminacy of these states makes a justice claim that acknowledges the salience of reemergent agency made possible by technological advance.

In this article, I will discuss the instrumentality of neuroprosthethics that have the potential to restore the communicative abilities of minimally conscious individuals so that they might more fully partake in human community. I will then turn to the challenge of how to reincorporate their reemergent voices into conversations that are material to their welfare, ones that relate to their self-determination and personal interests, while remaining cognizant of how these newfound abilities may be limited by residual deficits.

An earlier version of this article was presented to the Neuroethics Network on June 29, 2016 at Le Instiut du Cerveau et de la Moelle, CHU Pitié-Salpêtrière, Paris. This article is funded by a grant to the Consortium for the Advanced Study of Brain Injury (CASBI), at Weill Cornell Medical College by the Jerold B. Katz Foundation and partial support from the Qatar National Research Fund, award NPRP-7-380-5-051 on disability, law and ethics. The statements made herein are solely my own and not those of any funder or institutional affiliation. The author thanks Nancy Worthen and Elinor Quigley for the permission to tell their stories in print; Amy B. Ehrlich, Samantha Knowlton, and Nicholas D. Schiff for their comments; and Zoe M. Adams for her editorial support. 
Motivated to maximally reintegrate those lost to severe brain injury into the conversation, I will suggest a mosaic approach to decisionmaking, which seeks to achieve a proportionate and prudent balance between unbridled selfdetermination and conventional surrogate representation. This approach incorporates the views of the surrogate decisionmaker and the patient's prior wishes and current articulation, as well as the input of a medical professional and a patient advocate. Collectively, this group brings different shards of information together to construct a coherent picture, much the way small stones coalesce into a beautiful mosaic.

\section{Victims of Success?}

Over the past decade, neuroscience has made remarkable progress in restoring voice to patients in the minimally conscious state (MCS). ${ }^{2}$ MCS is disorder of consciousness that superficially resembles the better-known vegetative state, but that is distinguished by intact and functioning neural networks that can sustain liminal states of consciousness, and that forms the substrate for prosthetic communication. First codified in 2002, MCS patients superficially appear as if they are vegetative, but closer examination reveals that they are not. In contrast to the vegetative patient who presents with autonomic behaviors such as sleep-wake cycles, breathing, and startle reflexes grounded in the function of an intact brain stem, MCS patients occasionally demonstrate purposeful behavior. They intermittently demonstrate awareness of self, others, and their environment. They can demonstrate intention, attention, and memory; may say their name, reach for a cup, or track a family member when that person enters the room. The challenge is that because of the neurobiology of these patients-a disconnect among levels of arousal, thought, and action in what has been described as "cognitive motor dissociation" (CMD) ${ }^{3}$ - these behaviors are episodic and intermittent. Simply put, they are neither consistent nor reproducible.

Therefore, when families observe a purposeful behavior and the patient does not repeat it on demand when a clinician is present to validate their claim, their report is dismissed as wishful thinking, even though it is consistent with the biology of the condition. For these reasons and others that I have identified, the discordance between what might be happening inside the brain, and what is overtly manifested through observable behaviors, has led to catastrophic diagnostic error rates related to MCS. ${ }^{4}$

These errors have made the restoration of reliable functional communication the holy grail of those engaged in disorders of consciousness (DOC) research. Some notable success has been achieved along three lines of investigation: neuromodulation, neuroimaging, and pharmacology. None are validated therapies, but each reveals the progress that has been made and the need to develop anticipatory ethics to address challenges posed by reemergent agency.

In 2007, our team demonstrated the first use of deep brain stimulation in the MCS. ${ }^{5}$ An individual in MCS who had neither spoken nor eaten by mouth in the 6 years since his injury was, with stimulation to the bilateral intralaminar nuclei of the thalamus, able to say six or seven-word sentences and part of the Pledge of Allegiance, go shopping with his mother, and even tell her he loved her. He was also able to masticate, manage his secretions, and eat. This invasive technique has more recently been complemented by a provocative case report using noninvasive ultrasonic stimulation targeting the thalamus, which yielded transient improvements. ${ }^{6}$ 
In 2010, Martin Monti and colleagues used functional magnetic resonance imaging to establish a communication channel with a person thought to be in the vegetative state. ${ }^{7}$ The subject's volitional responses to questions, through corresponding flares on neuroimaging, had diagnostic implications: they demonstrated that he was in a state of nonbehavioral MCS. ${ }^{8}$ And when these responses were toggled to yes/no answers to questions, communication was reestablished with a person who otherwise would have been unable to communicate.

Drugs are the final neuroprosthetic. Zolpidem has been shown to increase awareness in patients in the MCS who might otherwise appear to be vegetative. ${ }^{9}$ Joseph Giacino and John Whyte demonstrated that the antiviral drug amantadine could accelerate improvement on the coma recovery and disability recovery scales in a randomized clinical trial through its dopaminergic effect. ${ }^{10}$

Added to this panoply of promising technology is the natural history of recovery from brain injury and the ability of the injured brain to repair itself over time. A remarkable study by my colleagues at Weill Cornell Medicine demonstrated structural changes in the brain of Margaret Worthen, ${ }^{11}$ the protagonist of my book, Rights Come to Mind: Brain Injury, Ethics and the Struggle for Consciousness ${ }^{12}$ over a half decade of longitudinal multimodal assessments.

Maggie had sustained a brain injury just before she was to graduate from Smith College. ${ }^{13}$ She was left in what was thought to be a vegetative state, but was found to be minimally conscious. With the aid of her loving mother, rehabilitation, and a simple eye-tracking device that allowed her to answer questions by moving her left eye up or down, she was able to reestablish rudimentary communication.
Thengone et al., using diffusion tensor functional neuroimaging, were able to document structural and functional changes in Maggie's brain during years following her injury. Over an extended period of time, Maggie's brain essentially rewired Broca's area, a region of the cortex critical for expressive speech. ${ }^{14}$ It was a remarkable and resounding demonstration of the resilience of the injured brain and its ability to harness a developmental mechanism to foster brain repair. ${ }^{15,16}$

Although none of these approaches have achieved the status of a vetted therapy or diagnostic approach, and recovery is never guaranteed, it is not premature to anticipate that this work will advance and present the ethical challenge of how to respond to a reemergent voice facilitated by neuroprosthetics and the resilience of the injured brain. To do otherwise would make patients with severe brain injury, who have the potential to again be heard, victims of medical and scientific success. This would silence their voices and constitute an injustice to their reemergent agency.

These individuals should not be silenced again because of scholarly inattention to the pressing challenge of how to allow them to participate in decisions and discussions that would have a bearing on their welfare and happiness. Along with improved prosthetics, these individuals are also entitled to a suitable and workable ethical framework that would allow them the opportunity to demonstrate their fullest will consistent with prudence.

\section{The Problem of Reemergent Voice}

Herein resides the problem. How is the maximal expression of reemergent agency allowed for without imposing a burden that cannot be responsibly maintained? For example, when Monti 
et al. first demonstrated functional neuroimaging's ability to serve as a communication channel in a patient thought to be vegetative but who was found to be minimally conscious, ${ }^{17}$ I was asked by the New York Times whether such interventions could allow a patient the opportunity to express a desire to die or refuse therapy. ${ }^{18}$ It was a logical and expected question, given the confluence of self-determination and the right to die in the United States ${ }^{19,20,21}$ and the perceptions that people with severe brain injury would want to die.

When I read the article, however, my initial thoughts were not of a right to die, or the continuation of a saga that has intermingled brain injury and the right to die movement since the case of Karen Ann Quinlan. Rather, it was an image of Nelson Mandela when he returned to the prison on Robben Island where he had been held captive by South Africa's apartheid regime because he had sought to counter that injustice..$^{22,23}$ I remembered him looking out through the bars that had confined him. The photograph captured his visionary gaze looking beyond to the sunshine and a new South Africa. I also thought of all the patients I had seen who had similarly been imprisoned in their own minds because their thoughts could not be expressed. Now, through this novel use of neuroimaging, patients saddled with a discordance of thought and action (here the act of speaking) could be liberated from their biological captivity. They could rejoin the broader human community when given access to communication. It was not, to my mind, about a right to die, but rather the right to live once again among the rest of us. In sum, the right to live a more fully human life, if that was their wish.

By the time the reporter asked me for a comment, however, reality had set in. What exactly should be the criteria to accept this technology as valid and allow for the expression of will, whether to use it to evince a desire to live or, for that matter, to die? How much credence should be given to neuroprosthetic communication? What kind of decisions should be acceptable? Should decisions to withdraw, much less withhold, life-sustaining therapies be included or excluded? Should limits be set on the scope of a patient's discretion and decisionmaking?

Amidst a full interview, therefore, I was quoted as saying, "We've opened up a communication channel with this technique, but in some ways it's like a very bad cell phone connection." 24 My quip not only sought to convey the wonder of hearing from silent minds ${ }^{25}$ imprisoned by brain injury, but also point to the real challenges posed by their liberation.

Yes, it is great news, but it is important not to jump to conclusions. There were, and are, serious technical and normative challenges to address before this technology can be ready for regular use. ${ }^{26}$ As an operational matter, patients in MCS are unable to initiate a question or to convey its content if they have one on their mind. This makes them dependent on their interlocutors in a manner that could deprive them of the chance to convey their own thinking. If the question asked does not match the thought that they wish to express, the thought will go unsaid and unspoken. Such absence of speech could lead to the mistaken inference that the lack of the spoken word meant a corresponding lack of thought. The right question might be asked but at the wrong time. Patients who are in MCS have problems with arousal, and, therefore, have a waxing and waning attention span. When this is coupled with impaired motor output, a patient's motoric and verbal output may not reflect the workings of that person's mind. ${ }^{27}$

My colleague, Nicholas Schiff, has called this phenomenon CMD. ${ }^{28} \mathrm{CMD}$ 
can be thought of as the decoupling of thought and behavior either because of impaired motor output or because the level of arousal necessary to sustain engagement with the outside world is lacking. This combination of factors may yield a non-answer on one occasion but not on another. A non-response could prompt a mistaken or flawed inference about global abilities even though that failure to respond was reflective of a temporary brain state. At other times, a patient could be capable of so much more.

Further compounding the challenge of fluctuating levels of arousal is the challenge of the potential latency of response. ${ }^{29}$ Patients may respond slowly, in fact so slowly that the response is missed. This is what happened when Maggie was studied using a volitional neuroimaging paradigm. ${ }^{30}$ Initially, we believed that she did not respond to our questions, only to later discover that her answers were so slowly forthcoming that they were buried in the following question. ${ }^{31}$ This was a function of her biology, but other individuals might be delayed in their responses because they were deliberating or weighing their choices carefully, and some might not respond because they intentionally chose not to do so.

To add to this are issues related to the the technology employed, much like that bad cell phone conversation referred to earlier. A non-response could simply be the function of a faulty methodology or inadequate bandwidth, all extrinsic variables independent of the patient's intrinsic ability to communicate. ${ }^{32}$

In the aggregate, this makes the interpretation of responses more useful when they are present rather than when they are not. A positive response, as in the case of the Monti et al. example, was a game changer, ${ }^{33}$ changing perceptions about a patient who was thought to be vegetative, and therefore permanently unconscious, but who was actually minimally conscious, albeit in a non-behavioral MCS in which there were thoughts but not overt motor output. ${ }^{34}$ But a nonresponse, for all the previously cited reasons, can never be dispositive. Given the limits of the available technology and the biology of MCS, the risk of a false negative is just too high.

The specificity of this methodology is not known, nor, even more fundamentally, is its sensitivity or its ability to detect consciousness when it is there. There is reason to be concerned as well when there is a negative response to a query. One of the great paradoxes, which remains unsettled to this day, is that some patients who can follow commands and satisfy bedside behavioral criteria for MCS are unable to (or perhaps care not to) follow commands in the scanner. Therefore, this makes the scanner insensitive to MCS. The best detector of MCS remains the psychometric test, the Coma Recovery Scale - Revised, ${ }^{35}$ which is performed at the bedside by a skilled examiner on multiple occasions in order to take account of fluctuations in levels of arousal and the individual's potential for engagement.

This suggests that positive responses are meaningful, whereas negative ones may be useless and even dangerous, because they could yield the false impression that the patient is unable to communicate when in fact the patient might retain that ability. This error is compounded by the seductive nature of neuroimaging technology and its compelling technological flourish. These questions prompt one to wonder if an individual's responses accurately reflect underlying thoughts and wishes. This indeterminacy, coupled with the consequences of being misunderstood or misconstrued, call for a communicative approach bolstered by safeguards and redundancies.

Nancy Worthen voiced similar concerns about the hypothetical situation 
of ceding authority to her daughter's emergent capabilities. In an interview performed years before the Thengone et al. study, Nancy was cautious:

if I asked her, do you think the quality of your life isn't enough. I don't know, what would I do if she said 'no mom, it's not enough...No, it just doesn't feel right to me. It doesn't feel like she's in a position to decide that because she's so vulnerable. I feel like I'd be taking advantage of her.. . . the only questions that she can answer are the ones I choose and so they're the only questions. I don't feel like I know what questions she wants me to ask. ${ }^{36}$

And beyond Maggie's vulnerability, Nancy was concerned about the everpresent risk of misconstrual:

Like so sometimes I think-there was a time where she's like she's moving and I am thinking she's angry whatever or she's in pain or... I was trying to interpret what I saw in Margaret and ... it turned out that she just wanted to go back to bed. Like it wasn't a big [deal]... it wasn't a what you call it ... [an] ethical crisis or some sort of metaphysical dilemma like "I want to die, like I'm so depressed." It was just a desire to go to bed, to stretch a leg, to work out a cramp. ${ }^{37}$

From experience, she has learned to be more cautious, noting "Whereas I might have interpreted it as something larger, it was just I'm tired and want to go to bed." 38

\section{Rationale for a Mosaic Approach}

To accommodate a patient's reemergent voice, yet not let it speak beyond its range and capabilities, any normative framework of analysis would need to have fail safes and multiple sources of input before decisions were undertaken. To that end, I will suggest a mosaic approach to decisionmaking for reemergent agency. Mosaics are made of small stones that come together. The whole emerges from the parts to create beautiful patterns when viewed from a distance. The same process can bring coherence to the capacity puzzle prompted by reemergent agency. Like a mosaic's shards that coalesce to create discernible patterns, pieces of information and perspectives can come together to create a coherent picture with the result being the inclusion of the patient's voice into the deliberative space prompted by reemergent voice and recovery.

Invoking the mosaic metaphor is useful for those with reemergent capacity, because in isolation, their piece of the capacity puzzle is insufficient to generate the desired image. And yet without their contribution, the pattern that emerges from the pieces will be incomplete, missing an essential element. Temporally, creating the artistry of a mosaic takes time, collecting the elements and then organizing a final product. Reaching a consensus on what to do similarly has a T1 (time 1) to T2 (time 2) component and is a constructed work. Finally at a meta-level, mosaics overcome fragmentation, and this speaks to the reintegration of individuals with their newly regained voice into civil society.

This suggestion moves out of the conventional realm of surrogate decisionmaking where the voice of the patient has been lost and the surrogate steps in to decide. In this familiar scenario, there is an exchange of the surrogate for the principal. In contrast, a mosaic approach requires the contributions of both the patient and surrogate, because neither has full normative authority or substantive knowledge to decide alone. 
The challenge of relying on either surrogate or patient becomes evident if one considers the difference between consent and assent, and between refusal and dissent. The surrogate would be legally empowered to consent and refuse in the absence of the patient's competence, but the patient might have the ability to voice assent or dissent, thus potentially informing the deliberative authority of the surrogate.

This makes unilateral surrogate judgments problematic, because the origin of their representational authority derives from the patient, either through delegation as through a durable power of attorney for healthcare, or from substantive knowledge of prior wishes, and familial relations. In all of these cases, the surrogate's authority derives from the patient's right of self-determination. Logically, if surrogate authority derives from the patient when there is incapacity, it follows that the same is true as it returns. To do otherwise discounts reemergent voice and dishonors the source of the surrogate's moral authority. Therefore, for consistency, both prior wishes and current articulations of preferences need to be heard and deliberated on. At least some level of deference is owed to the partially capacitated, reemergent patient, as neither surrogate nor patient can decide alone once there is reemergent voice.

This deference needs mediation beyond patient and surrogate to ensure that the reemergent voice is heard. A patient might have the ability to articulate a view or preference but might not have the wherewithal to gain a proper hearing. Surrogates who have been used to making all the decisions will have a hard time ceding their responsibilities, and clinicians will continue to look to surrogates for direction out of habit and convenience. To ensure that the patient is heard, others need to be added to the mix to counter the status quo, which would seem to perpetuate an unreconstructed role for the surrogate.

\section{Creating the Mosaic}

Under the framework of mosaic decisionmaking, the deliberate process would include surrogate and patient, a medical professional, and a patient advocate. Throughout, the group would be guided by the patient's prior wishes, medical best interest, and the patient's current, if inchoate views. These individuals and this information come together metaphorically into a mosaic.

This consensus model for mosaic decisionmaking ${ }^{39}$ is based on a process used by the New York State Commission on Quality Care for the Mentally Ill, which makes decisions for isolated incapacitated patients with mental illness. ${ }^{40}$ In the absence of family members or other surrogates, the Commission assembles surrogate decisionmaking committees (SDMCs) to reach a consensus on major medical decisions. SDMCs are made up of 12 members, and operate in smaller groups of 4 members drawn from a larger panel with representatives from the following categories: New York State health professionals, former patients or relatives of people with mentally disability, attorneys, and advocates for the mentally disabled and/or experts with interest in their care. ${ }^{41}$

This process is in lieu of going to court, which can be costly and can delay care, ${ }^{42}$ or of more expeditious routes to treatment decisions that often skirt questions of proper representation and, ultimately, informed consent. Follow-up data from this program suggest that this mechanism expedites decisionmaking and improves the quality of the decisionmaking process. As evidence of the quality of their deliberations, follow-up data reveal that the process finds some patients to be 
competent, identifies unknown surrogates, utilizes second opinions, modifies treatment decisions, and refuses consent in a small number of cases. ${ }^{43}$

Like the model used in New York, a mosaic decisionmaking ensemble would work together to titrate the patient's voice as maximally as possible, tempered by countervailing information and perspectives. Each member of the group would have a specific role in the deliberation.

The surrogate decisionmaker would take the lead in the hierarchy of decisionmakers, as the person most proximally placed to the patient (unlike New York's SDMCs where there is no available surrogate). The surrogate would be informed by the patient's prior wishes and be best positioned to interpret the patient's current views. Additional deference would be owed to the surrogate if that person had been specifically delegated as a durable power of attorney for healthcare prior to the patient's decisional incapacity.

Because of the surrogate's relationship to the patient, and the primacy of negative over positive rights which stem from the right to be left alone, the surrogate would have veto power over any decision emerging from mosaic deliberations. Nothing could be done without surrogate agreement, unless it was ordered by a court of appropriate jurisdiction. Conversely, given the emergence of patient's voice, the surrogate would have less authority to consent than if the patient were unable to participate at all.

Although the surrogate's agreement would be necessary, it might not be sufficient absent the integration of the views of the patient and the larger group. This is to protect the patient from unilateral surrogate decisions and also to mitigate decisions made by surrogates whose frustration might make them desperate for a "cure," even if the risks were disproportionate and excessive.
Conversely, a frustrated surrogate might withdraw care without adequate consultation with the patient who might evince a preference.

The countervailing views of the mosaic group would seek to temper outlier decisions (in either direction) and help achieve a consensus determination. It would seek to achieve this degree of integration by drawing on the views of each of its members. The medical professional would provide guidance on the specifics of any care decision and be an advocate for the patient. The patient advocate, who would need to have had experience with brain injury as a survivor or a caregiver, would help ensure that the patient's views were maximally incorporated into the decisionmaking process. The advocate would work to advance the patient's views and help ensure that the patient received the assistance necessary to be most expressive. ${ }^{44}$

\section{Thresholds for Patient Engagement}

Collectively, this group would seek to determine thresholds to help titrate the patient's voice. This process would look much like James Drane's formulation of the sliding scale of competence for informed consent. ${ }^{45}$ In that framework, the patient's ability to partake in decisions is tied to his or her ability to understand the question under consideration, integrate the relevant information, and evidence heightened degrees of "evidencing understanding." But how does one determine this, when the speech act could be suspect and non-responses are potentially exercises in ambiguity?

The narrative of the Quigleys, another family I interviewed, may provide guidance on the threshold question. ${ }^{46}$ Kenny Quigley had been placed in a group home after an extended stay in a nursing home after his traumatic brain injury. ${ }^{47}$ His mother, Elinor, liked the social 
aspects that the group home provided her son, but was concerned about the quality of medical care. It was a borderline situation that required balancing of the friendships that Kenny was making after the isolation of chronic care and the availability of on-site medical care.

Elinor and Kenny's wife were inclined to move him out of the group home, but wanted to know what Kenny thought, as best they could discern it. Even when he was functionally more impaired, they sought to know his views and wishes. As Elinor explained, even when Kenny was less capable of expressing himself, she and her family would seek to understand him. Instead of discounting his views, she noted, "No we would still weigh it you know, we never undervalued his opinion. We would weigh it, talk about it, and see, does he really know? Does he really understand what he's doing or what he's saying, you know?"

When it came time to decide about the group home, they had heard enough from Kenny to change their minds and let him stay. As criteria for their change of heart, they pointed to the persistence of Kenny's view, as well as his actions. This constituted evidence of his wishes and level of understanding. Elinor said. "I asked him: 'Kenny are you happy here, do you want to leave?' and he said 'no.' I said, 'Are you happy here?' he said 'yes.' So I said 'wow, we'll try to figure out what we can do now.' So my feelings, his wife's feelings, and the group home's feelings...to get a happy medium so that's what we did. We all worked together but Kenny was happy there. He didn't want to leave." 48

When asked how to know when to listen to him, and when to discard what he was saying, Elinor responded: "Well mostly because he's persistent. If he's persistent I know he knows like it wasn't just once I asked, 'Do you want to be here? Do you want to go back to a nursing home? Are you happy here?' And he'll say, he was saying, 'Yes I'm happy.' And so it wasn't just once we asked. It would be different times, different days, you know." 49

The Quigleys also looked at what Kenny did. His actions reinforced his words. Elinor reports that even as she was looking at other facilities, "he just convinced me he was happy because of the way he walked around, the way he did things." She explained, "He took charge of himself you know? ...we'd be in the parlor and he would just turn his wheelchair and go into his room and look back like, this is my room you know? I mean he just showed he belonged there." In sum, it was this combination of Kenny's words and deeds that showed that he understood the choice at hand and conveyed his desire to stay in the group home.

Although it was something more. Mr. Quigley's family respected him and his personhood. When it was suggested that he would be better off if others, more capable than he, made decisions, that it would be safer than listening to someone so "impaired," they bristled at the suggestion. Here is another dose of experiential wisdom from Elinor Quigley. "Well that's hard to do because, um, it's very difficult to explain to people that even if all they have is an eighth of an idea of what they wanna do, that eighth is important and it's very hard to...like we said, unless you've experienced something like it you can't explain to anybody, you know?"50

Why was that eighth important? Kenny's sister replied, "'cause he's a person...He still has feelings you know, right?" Elinor added, "Yeah. It's all about him. I mean he wouldn't take that right away from me you know? I can't take it away from him." Although the goal was to protect him, Mrs. Quigley said, "we try to give him 
independence too." It does not always lead to a choice by her son, however, because "Sometimes he doesn't want to do any of it, but he's given a choice anyway." 51

The bottom line underlying the family's approach is "We try to recognize that he is a human. He is a person just like a little baby now you know? I mean you give a baby choices." 52 It is an a posteriori statement borne of experience and mother's love, which speaks to the centrality of reemergent voice to personhood, and to why structures need to be advanced that will do for others what the Quigleys are struggling to do for Kenny.

\section{Caveats}

As instrumental as this mosaic process of decisionmaking might be, I do not suggest it without reservations. My greatest concern, for which I do not have a procedural solution, is how to choose the members of the mosaic team, most notably the individual who would serve as the patient advocate. Although the patient, surrogate, and physician are fixed by circumstances, the advocate is not. How that person is chosen, trained, and brought into the mix may determine the success or failure of this experiment in deliberation and consensus building. At the very least, these people should be vetted, trained, and given prospective guidance about their role and responsibilities.

A second concern is that a mosaic approach disempowers surrogates who traditionally have made decisions for incapacitated patients. This limitation will occur in the name of increasing the authority of reemerging patients. Seen from the usual dichotomy of patient or surrogate consent, this trade-off can be viewed as a zero sum game in which one's gain is the other's loss. This may lead to surrogate resentment of the patient and the process, potentially leading to disengagement or outright abdication of the role.

More concerning would be the misuse of the mosaic structure that I recommend. I could envision an unholy alliance between the physician and advocate that alienated and isolated wellintentioned surrogates, who likely know their loved ones' wishes better than anyone else. These surrogates already feel frustrated by their experiences working with the healthcare system. I have written a book on their travails, ${ }^{53}$ and the last thing that I would want to do would be to add to their angst by adding another bureaucratic obstacle that they would have to overcome.

Given this reservation, my appeal for a mosaic approach for decisionmaking is more a heuristic than a practice guideline. It is offered here to suggest a means of ensuring the reintegration of the patient's returning voice into the conversation. It is not intended to deny surrogates their proper role, but rather to remind them (and the clinical team engaged in care) that patients in their emerging state deserves to be heard. The goal is simply an inclusive conversation.

This clarion call to hear, and revel in the returning voice of recovering patients, is not meant to alienate or marginalize surrogates. Rather it is to help them better appreciate the moral significance of their representational efforts in light of the patient's reemergent agency, and as surrogates appreciate this new phase in their representation, all who form this mosaic of care should view surrogates as central to any decision. They should be respected throughout the process and become neither alienated nor isolated, and they should be utilized for their unique translational abilities to understand what their loved ones are saying, or trying to say.

Lest it be forgotten, as interpreters of their children's new found capacities, 
Nancy and Elinor were better positioned than anyone else to be their advocates, albeit in a more nuanced manner. As Maggie ${ }^{54}$ and Kenny found their way to communication, their mothers' voices were strengthened and emboldened as they welcomed their children back into the conversation.

That is not to say that there would not be disagreements as patients recover and become more independent. But that would be a good thing. It would be a sign of evolving autonomy, 55 a welcome development reminiscent of an earlier developmental transition that adolescents make as they journey into adulthood and parents nervously cede their authority. This journey is not easy whenever it happens, but when it occurs out of the depths of brain injury, it is a time for rejoicing and celebration. Given the progress that neuroscience is poised to make, this is a journey for which the neuroethics community must now prepare.

\section{Notes}

1. Fins JJ. Neuroethics and neurotechnology: Instrumentality and human rights. In: Illes J, Hossain S, eds. Neuroethics: Anticipating the Future. New York: Oxford University Press, In Press.

2. Giacino JT, Ashwal S, Childs N, Cranford R, Jennett B, Katz DI, et al. The minimally conscious state: definition and diagnostic criteria. Neurology 2002;58(3):349-53.

3. Schiff ND. Cognitive motor dissociation following severe brain injuries. JAMA Neurology. 2015;72(12):1413-5.

4. Schnakers C, Vanhaudenhuyse A, Giacino J, Ventura M, Boly M, Majerus S, et al. Diagnostic accuracy of the vegetative and minimally conscious state: Clinical consensus versus standardized neurobehavioral assessment. BMC Neurology 2009;9:35.

5. Schiff ND, Giacino JT, Kalmar K, Victor JD, Baker K, Gerber M, et al. Behavioral improvements with thalamic stimulation after severe traumatic brain injury. Nature 2007;448(7153): 600-603.

6. Monti MM, Schnakers C, Korb AS, Bystritsky A, Vespa PM. Non-invasive ultrasonic thalamic stimulation in disorders of consciousness after severe brain injury: a first-in-man report. Brain Stimulation 2016;9(6):940-1.

7. Monti MM, Vanhaudenhuyse A, Coleman MR, Boly M, Pickard JD, Tshibanda L, et al. Willful modulation of brain activity in disorders of consciousness. New England Journal of Medicine 2010;362(7):579-89.

8. Fins JJ, Schiff ND. Shades of gray: New insights from the vegetative state. The Hastings Center Report 2006;36(6):8.

9. Chatelle C, Thibaut A, Gosseries O, Bruno MA, Demertzi A, Bernard C, et al. Changes in cerebral metabolism in patients with a minimally conscious state responding to zolpidem. Frontiers in Human Neuroscience 2014;8:917.

10. Giacino JT, Whyte J, Bagiella E, Kalmar K, Childs N, Khademi A, et al. Placebocontrolled trial of amantadine for severe traumatic brain injury. New England Journal of Medicine 2012;366(9):819-26.

11. Thengone DJ, Voss HU, Fridman EA, Schiff ND. Local changes in network structure contribute to late communication recovery after severe brain injury. Science Translational Medicine 2016;8(368):368re5.

12. Fins JJ. Rights Come to Mind: Brain Injury, Ethics and the Struggle for Consciousness. New York: Cambridge University Press; 2015.

13. See note 12, Fins 2015.

14. See note 11, Thengone et al. 2016.

15. See note 12, Fins 2015.

16. Wright MS, Fins JJ. Rehabilitation, education, and the integration of individuals with severe brain injury into civil society: Towards an expanded rights agenda in response to new insights from translational neuroethics and neuroscience. Yale Journal of Health Policy, Law, and Ethics 2016;16(2):233-88.

17. See note 7, Monti el al. 2010.

18. Carey B. Inside the injured brain, many kinds of awareness. The New York Times, April 5, 2005; available at http: / / www.nytimes.com/ (last accessed 15 May 2017).

19. Fins JJ. Constructing an ethical stereotaxy for severe brain injury: balancing risks, benefits and access. Nature Reviews Neuroscience 2003;4:323-7.

20. Fins JJ. Affirming the right to care, preserving the right to die: Disorders of consciousness and neuroethics after Schiavo. 2006;4(2):169-78.

21. See note 12, Fins 2015.

22. Mandela N. Long Walk to Freedom. New York: Little, Brown and Company; 1994.

23. See note 1 , Fins In Press.

24. Fins JJ. Quotation of the day. The New York Times, A-20, February 4, 2010; available at https: / query.nytimes.com/gst/fullpage. html?res=9405E5D8143FF937A35751C0A966 9D8B63 (last accessed 3 May 2017). 
25. Fins JJ, Schiff ND. In search of silent minds. Scientific American Mind, November/December 2016; 44-51.

26. Fins JJ, Schiff ND. In the blink of the mind's eye. The Hastings Center Report 2010;40(3): 21-3.

27. Giacino JT, Fins JJ, Laureys S, Schiff ND. Disorders of consciousness after acquired brain injury: The state of the science. Nature Reviews Neurology 2014;10:99-114.

28. See note 3, Schiff 2015.

29. See note 26, Fins, Schiff 2010.

30. Bardin JC, Fins JJ, Katz DI, Hersh J, Heier LA, Tabelow K, et al. Dissociations between behavioural and functional magnetic resonance imaging-based evaluations of cognitive function. Brain 2011;134(3):769-82.

31. Fins JJ. "Wait, Wait-Don't Tell Me"...Tuning in the Injured Brain. Archives of Neurology 2012;69(2):158-60.

32. See note 26, Fins, Schiff 2010.

33. See note 7, Monti el al. 2010.

34. With further assessment, this individual did subsequently meet the behavioral criteria for MCS.

35. Giacino JT, Kalmar K and Whyte J. The JFK Coma Recovery Scale-Revised: Measurement characteristics and diagnostic utility. Archives of Physical Medicine and Rehabilitation 2004;85(22): 2020-9.

36. See note 12, Fins 2015, at 283.

37. See note 12, Fins 2015, at 284.

38. See note 12, Fins 2015, at 284.

39. Fins JJ, Miller FG. Enrolling decisionally incapacitated subjects in neuropsychiatric research. CNS Spectrums 2000;5(10):32-42.

40. Sundram CJ. Informed consent for major medical treatment of mentally disabled people. A new approach. New England Journal of Medicine 1988;318(21):1368-73.

41. NY Mental Hygeine Law, Art. 80.
42. New York State Justice Center for the Protection of People with Special Needs. Surrogate Decision Making Committee Program: Panel Member Handbook. May 2017; available at: https:// www.justicecenter.ny.gov / sites/default/ files / documents /SDMC-Handbook_1.pdf (last accessed on 12 June 2017).

43. Sundram CJ, Stavis PF. Obtaining informed consent for treatment of mentally incompetent patients. A decade under New York's innovative approach. International Journal of Law and Psychiatry. 1999;22(2):107-23.

44. Bach M, Kerzner L. Advancing substantive equality for persons with disabilities through law, policy and practice. Commissioned by the Law Commission of Ontario, 2010; available at: http:/ /www.lcocdo.org/disabilitiescommissioned-paper-bach-kerzner.pdf (last accessed 15 May 2017).

45. Drane JF. Competency to give an informed consent. A model for making clinical assessments. JAMA 1984;252(7):925-7.

46. IRB approved interview by author with Elinor Quigley on April 12, 2017, Weill Cornell Medical College. Permission granted for quotation.

47. See note 12, Fins 2015.

48. See note 46, Quigley interview.

49. See note 46, Quigley interview.

50. See note 46, Quigley interview.

51. See note 46, Quigley interview.

52. See note 46, Quigley interview.

53. See note 12, Fins 2015.

54. Fins JJ. Giving voice to consciousness: Neuroethics, human rights and the indispensability of neuroscience. The Society for Neuroscience David Kopf Lecture on Neuroethics. Cambridge Quarterly of Health Care Ethics 2016;25(4):583-99.

55. Fleischman AR. Pediatric Ethics: Protecting the Interests of Children. New York: Oxford University Press; 2016. 